\title{
About buckling of X-type bracing
}

\section{Gancia Gian Michele}

Dep. Architecture Sciences, Genoa Polytechnic School, Genoa, Italy

\section{Email address:}

gancia@arch.unige.it

\section{To cite this article:}

Gancia Gian Michele. About Buckling of X-Type Bracing. International Journal of Science, Technology and Society. Vol. 2, No. 4, 2014, pp. 69-72. doi: 10.11648/j.ijsts.20140204.12

\begin{abstract}
In X-type bracing structures generally it does not take into account the structural contribution of the compressed member, since it is assumed to have a negligible compressive strength; it considered that the stretched member takes the total stress. In the following we analyse as the stretched diagonal, joined in the middle to the compressed one, improves the structural behaviour of this both with respect to the buckling in-plane or out-of -plane of the structure. First we recall the link between the Euler buckling load of a rod free and braced depending on the stiffness $\mathrm{k}$ of the brace. Then we analyse the in-plane and out-of-plane buckling of the rod and, for the two situations, we value the increase of the buckling load due to the elastic brace. In the end for both cases we show in what condition the stretched rod causes that the compressed one buckles in the second mode.
\end{abstract}

Keywords: Steel Bracing Frame, Buckling of Steel Structure, X-Type Diagonal Bracing

\section{Introduction}

The bracing elements in steel structures have the twofold function to take the structural actions due to horizontal loads, such as wind and earthquake, and to ensure the overall stability of the building to which they belong, so you need to have a high stiffness to limit maximum displacements.

To ensure bracing good stiffness and to control the weights lattice girders with X-type wall bracing are used.

For these girders the structural contribution of the compressed rods is ignored, since it is assumed to have a negligible compressive strength, while the structural function is assigned only to the stretched one.

The purpose of this paper is to define how the stretched rod contributes to reduce the compressed rod effective length, connected to it, to increase its Euler buckling load and therefore the possibility of the compressed rod to effectively contribute to the bracing strength.

We recall from the problem of the compressed rod elastically braced raised in [1] for different cases that was later taken, among others, in [2], [3], [4], [5] with reference to civil and industrial buildings and to steel bridges in [6] [7] [8] [9].

Then we consider the contribution of the stretched rod to the stability of the compressed one as a displacement constraint in-plane and out-of -plane of the structure.

In both situations we look for the condition for which the effective length of the compressed rod can be considered equal to half of the geometric length.

\section{Stability of an Elastically Braced Compressed Rod}

With reference to the bracing structure shown in [Fig.1] we outline the compressed diagonal braced in the middle by an elastic constraint [Fig.2].

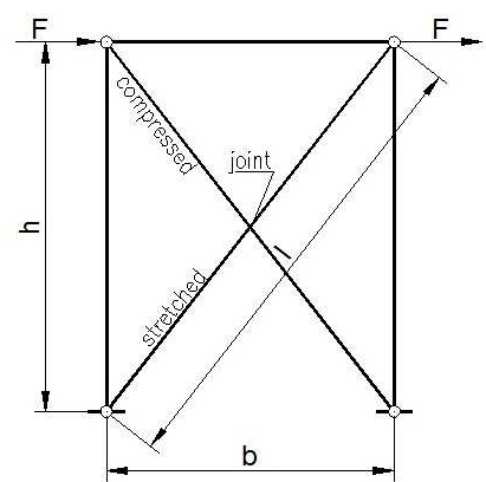

Figure 1. X-type bracing structure 


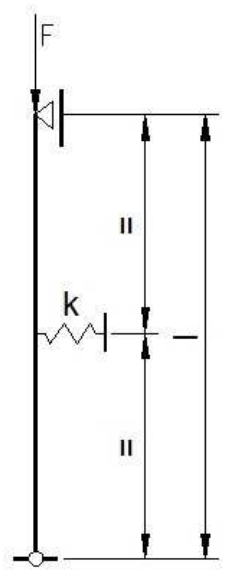

Figure 2. Static scheme for the compressed diagonal

It is well known that, with reference to a changed equilibrium shape and for small displacement y (z), we have:

$$
\operatorname{EJy}{ }^{\prime \prime}(z)=-F y(z)+k y_{c} z / 2
$$

that putting

$$
\mathrm{a}^{2}=\mathrm{F} / \mathrm{EJ}
$$

leads to

$$
y^{\prime \prime}(z)+a^{2} y(z)=a^{2} k y_{c} z / 2 F
$$

and, using the boundary conditions $\mathrm{y}(0)=0$ e $\mathrm{y}(1 / 2)=\mathrm{y}_{\mathrm{c}}$, to the general solution in term of displacement

$$
\mathrm{y}(\mathrm{z})=\left(\mathrm{y}_{\mathrm{c}} / \sin \mathrm{al} / 2\right)(1-\mathrm{kl} / 4 \mathrm{~F}) \sin \mathrm{az}+\mathrm{ky}_{\mathrm{c}} \mathrm{z} / 2 \mathrm{~F}
$$

The further boundary condition $y^{\prime}(1 / 2)=0$ leads to

$$
\left(\mathrm{y}_{\mathrm{c}} / \sin \mathrm{al} / 2\right)(1-\mathrm{kl} / 4 \mathrm{~F}) \mathrm{a} \cos \mathrm{az}+\mathrm{ky}_{\mathrm{c}} / 2 \mathrm{~F}=0
$$

and for $\mathrm{y}_{\mathrm{c}} \mathrm{k} / 2 \mathrm{~F} \neq 0$ it becomes

$$
\mathrm{al} / 2-\operatorname{tg} \mathrm{al} / 2=2 \mathrm{aF} / \mathrm{k}
$$

and also from [1]

$$
(\mathrm{t}-\operatorname{tg} \mathrm{t}) / \mathrm{t}^{3}=16 \mathrm{P}_{\mathrm{E}} / \pi^{2} \mathrm{kl}
$$

in which

$$
\mathrm{t}=\mathrm{al} / 2
$$

and $\mathrm{P}_{\mathrm{E}}$ is the Euler buckling load of the compressed rod not braced.

Numerically solving the (7) we obtain $t$ and from (8)

$$
\mathrm{P}_{\mathrm{cr}}=\mathrm{P}_{\mathrm{E}} 4 \mathrm{t}^{2} / \pi^{2}
$$

where $4 \mathrm{t}^{2} / \pi^{2}$ represents the Euler buckling load increase of the compressed rod due to the elastic constraint.

\section{Bracing in-Plane Stability of the Compressed Rod}

In the following we want to give an account of what is generally considered in the project and also admitted by some technical codes [10], [11], for which, with reference to $\mathrm{X}$-type diagonals connected to each other at the middle, the buckling length in the plane of the beam is equal to 0.51 and then

$$
\mathrm{P}_{\mathrm{cr}}=4 \mathrm{P}_{\mathrm{E}} \text {. }
$$

From the (9) we obtain

$$
4 \mathrm{P}_{\mathrm{E}}=\mathrm{P}_{\mathrm{E}} 4 \mathrm{t}^{2} / \pi^{2}
$$

from which results $\mathrm{t}=\pi$

and

$$
(\mathrm{t}-\operatorname{tg} \mathrm{t}) / \mathrm{t}^{3}=0.1015
$$

Now with reference to the (7) and considering $\mathrm{k}=2 \mathrm{EA} / \mathrm{s} / 1_{\mathrm{s}}$, where $A_{s}$ and $l_{s}$ are the area and the length of the tensile rod respectively, it becomes

$$
(\mathrm{t}-\operatorname{tg} \mathrm{t}) / \mathrm{t}^{3}=16 \mathrm{P}_{\mathrm{E}} / \pi^{2}\left(2 \mathrm{EA}_{\mathrm{s}} / 1_{\mathrm{s}}\right) 1_{\mathrm{c}}
$$

where $l_{c}$ is the length of the unbraced compressed rod.

Now from the expression of the Euler buckling load and of the inertia radius

$$
\mathrm{P}_{\mathrm{E}}=\pi^{2} \mathrm{EJ} / \mathrm{l}_{\mathrm{c}}^{2} \quad \mathrm{i}^{2}=\mathrm{J} / \mathrm{A}_{\mathrm{c}}
$$

the (12) is reduced to

$$
(\mathrm{t}-\operatorname{tg} \mathrm{t}) / \mathrm{t}^{3}=8 \Delta \mathrm{A} / \lambda^{2} \Delta \mathrm{l}
$$

with $\Delta \mathrm{A}=\mathrm{A}_{\mathrm{c}} / \mathrm{A}_{\mathrm{s}}, \Delta \mathrm{l}=\mathrm{l}_{\mathrm{c}} / \mathrm{l}_{\mathrm{s}}$ and $\lambda$ is the slenderness of the unbraced compressed rod.

If we equalize the left-hands of (11) e (13) we obtain

$$
\Delta \mathrm{A}=0.0127 \lambda^{2} \Delta \mathrm{l}
$$

that connects the areas of the stretched and compressed rods with the respective lengths to ensure that the stretched rod carries out a brace such that the effective length of the compressed rod results 0.51

If we consider $\Delta \mathrm{A}$ in the interval $60<=\lambda<=250$, limits between the squat and slender truss, and we remark that for $\mathrm{X}$-type diagonals $\Delta \mathrm{l}=1$ from (14) it derives

$$
\begin{gathered}
\Delta \mathrm{A}(60)=45.72 \text { e } \mathrm{A}_{\mathrm{s}}=2.20 \% \mathrm{~A}_{\mathrm{c}} \\
\Delta \mathrm{A}(250)=793.75 \mathrm{eA}_{\mathrm{s}}=0.126 \% \mathrm{~A}_{\mathrm{c}}
\end{gathered}
$$

Therefore it is enough a weak constraint to reduce the rod effective length to 0.51 .

For an example we think of a section bar L90x9, $300 \mathrm{~cm}$ in length, with area $A_{c}=15.5 \mathrm{~cm}^{2}$ and inertia radius $i_{\min }=$ $1.76 \mathrm{~cm}$; the slenderness is $\lambda=170$ and so from (14) results $\mathrm{A}_{\mathrm{s}}=0.271 \% \mathrm{~A}_{\mathrm{c}}$ and $\mathrm{A}_{\mathrm{s}}=0.042 \mathrm{~cm}^{2}$.

A rod of $2.3 \mathrm{~mm}$ in diameter is enough to efficaciously brace the compressed rod and to impose that its effective length is equal to 0.51 . 


\section{Bracing Out-of-Plane Stability of the Compressed Rod}

In general in the structural design of X-type bracing we ignore the structural behaviour of the compressed diagonal, considered to have negligible capacity, and the whole resistance is entrusted to the stretched diagonal.

However the stretched rod elastically braces the compressed one with a own stiffness $\mathrm{k}$, that depends to its traction force $\mathrm{N}_{\mathrm{s}}$ and to its bending stiffness $\mathrm{EJ} / \mathrm{l}^{3}$.

Also in this case it is possible to refer to the (7)

$$
(\mathrm{t}-\operatorname{tg} \mathrm{t}) / \mathrm{t}^{3}=16 \mathrm{P}_{\mathrm{E}} / \pi^{2} \mathrm{kl}
$$

where $\mathrm{k}$, from [3], is

$$
\mathrm{k}=4 \mathrm{~N}_{\mathrm{s}} / 1_{\mathrm{s}}\left\{1 /\left[1-\tanh \left(\mathrm{a}_{\mathrm{s}} \mathrm{l}_{\mathrm{s}} / 2\right) /\left(\mathrm{a}_{\mathrm{s}} \mathrm{l}_{\mathrm{s}} / 2\right)\right]\right\}=4 \mathrm{~N}_{\mathrm{s}} / \mathrm{l}_{\mathrm{s}} \beta
$$

where

$$
\mathrm{a}_{\mathrm{s}}^{2}=\mathrm{N}_{\mathrm{s}} / \mathrm{EJ}_{\mathrm{s}}
$$

and

$$
\beta=\left\{1 /\left[1-\tanh \left(a_{s} 1_{s} / 2\right) /\left(a_{s} 1_{s} / 2\right)\right]\right\}
$$

We remark that for $J_{s} \rightarrow 0 \beta=1$ so, from (17), we obtain the stiffness $\mathrm{k}$ of a rope tight from $\mathrm{N}_{\mathrm{s}}$.

Replacing now the (15) in the (7) we have

$$
(\mathrm{t}-\operatorname{tg} \mathrm{t}) / \mathrm{t}^{3}=\left(4 / \pi^{2} \beta\right)(\Delta \mathrm{F} / \Delta \mathrm{l})
$$

in which

$$
\Delta \mathrm{F}=\mathrm{P}_{\mathrm{E}} / \mathrm{N}_{\mathrm{s}}
$$

and if $\Delta \mathrm{l}=1$ then

$$
(\mathrm{t}-\operatorname{tg} \mathrm{t}) / \mathrm{t}^{3}=\left(4 / \pi^{2} \beta\right) \Delta \mathrm{F}
$$

The determining of $t$ and $P_{c r}$, from the (9), of the compressed rod elastically braced depends on $\Delta \mathrm{F}$ e $\beta$, that depends on $\Delta \mathrm{F}$ too, in fact from the (8)

$$
\mathrm{t}^{2}=\mathrm{a}_{\mathrm{s}}^{2} 1^{2} / 4=\left(\mathrm{N}_{\mathrm{s}} / \mathrm{EJ}\right) 1^{2} / 4
$$

and also

$$
\mathrm{a}_{\mathrm{s}}^{2} 1^{2} / 4=\left(\mathrm{N}_{\mathrm{s}} / \mathrm{P}_{\mathrm{E}}\right) \pi^{2} / 4
$$

from which

$$
\mathrm{a}_{\mathrm{s}} 1 / 2=(\Delta \mathrm{F})^{-1 / 2} \pi / 2
$$

Then the (17) changes into

$$
\left.\beta=\left\{1 /\left[1-\tanh (\Delta \mathrm{F})^{-1 / 2} \pi / 2 /(\Delta \mathrm{F})^{-1 / 2} \pi / 2\right)\right]\right\}
$$

in this way, defined $\Delta \mathrm{F}$, we can fix $\beta$, $t$ and, from the (9), the new Euler buckling load $P_{c r}$ of the elastically braced compressed rod

$$
\mathrm{P}_{\mathrm{cr}}=\mathrm{P}_{\mathrm{E}} 4 \mathrm{t}^{2} / \pi^{2}
$$

and the relative new effective length

$$
1_{0}=(\pi / 2 \mathrm{t}) 1_{\mathrm{c}}
$$

From the (25) derives that the compressed rod buckle in the second mode, $\mathrm{l}_{0}=0.5 \mathrm{l}_{\mathrm{c}}$, when $\mathrm{t}=\pi$ and then from the (20) follows

$$
\left(4 / \pi^{2} \beta\right) \Delta \mathrm{F}=0.1013
$$

that numerically solved gives rise to

$$
\Delta \mathrm{F}=\mathrm{P}_{\mathrm{E}} / \mathrm{N}_{\mathrm{s}}=0.4
$$

and also to

$$
\mathrm{N}_{\mathrm{s}}=2.35 \mathrm{P}_{\mathrm{E}}
$$

so for $\Delta \mathrm{F}>0.425$ the compressed rod buckles in the second mode.

We remark that also for smaller tight force, $\Delta \mathrm{F}=1 \mathrm{o} \Delta \mathrm{F}=$ 0.5 , the effective length of the compressed rod is lower than $0.61_{\text {c. }}$.

Now since the (27) links the stress $\mathrm{N}_{\mathrm{s}}$ of the tensile rod with the Euler buckling load $\mathrm{P}_{\mathrm{E}}$ of the not braced compressed, it is necessary to check if the value of $\mathrm{N}_{\mathrm{s}}$, requisite to secure the brace for the compressed rod, isn't a strength limit for the same stretched rod.

So with reference to the steel design stress $f_{d}$ and the Euler critical stress $\sigma_{\mathrm{cr}, \mathrm{E}}(\lambda)=\mathrm{P}_{\mathrm{E}} / \mathrm{A}_{\mathrm{c}}=\pi^{2} \mathrm{E} / \lambda^{2}$ of the compressed rod the (27) changes in

$$
\mathrm{f}_{\mathrm{d}}=2.35 \sigma_{\mathrm{cr}, \mathrm{E}}(\lambda) \mathrm{A}_{\mathrm{c}} / \mathrm{A}_{\mathrm{s}}=2.35 \sigma_{\mathrm{cr}, \mathrm{E}}(\lambda) \Delta \mathrm{A}
$$

or

$$
\sigma_{\mathrm{cr}, \mathrm{E}}(\lambda)=\mathrm{f}_{\mathrm{d}} / 2.35 \Delta \mathrm{A}
$$

Now solving for $\lambda$, the slenderness of the not braced compressive rod, we can obtain the value of the length 1 besides the stretched rod leads efficaciously the function of constraint so that the compressed one buckles in the second mode.

For lower values of $\lambda$ the stretched rod can't make the brace function as for the value of $\mathrm{N}_{\mathrm{s}}$ would exceed the steel mechanical strength.

\section{Conclusions}

In the X-type diagonal bracing the stretched rod carry on a leading role for the structural capacity of the compressed one, that generally is ignored.

With reference to the compressed rod elastic stability in the structure in-plane, it has been found as the hypothesis of an effective length equal to the half of its geometrical length is admissible, in fact is enough a stretched rod with the area equal to the $2.2 \%$ of the compressed rod to manage it to buckle in the second mode.

The stretched rod carries on an important role with reference to the out-of-plane compressed rod stability too.

Its action, that depends from $\Delta \mathrm{F}=\mathrm{P}_{\mathrm{E}} / \mathrm{N}_{\mathrm{s}}$, is considerable already for $\Delta \mathrm{F}$ values near to the unit; in fact for $\Delta \mathrm{F}=1$ the Euler buckling load of the brace compressed rod is $\mathrm{P}_{\mathrm{cr}}=$ 


\section{$2.89 \mathrm{P}_{\mathrm{E}}$}

If the stretched rod stress is $\mathrm{N}_{\mathrm{s}}=2.35 \mathrm{P}_{\mathrm{E}}$ then $\mathrm{P}_{\mathrm{cr}}=4 \mathrm{P}_{\mathrm{E}}$ and the compressed rod buckles in the second mode.

It is necessary to note that as the stretched rod stress $\mathrm{N}_{\mathrm{s}}$, useful to impose the buckling in the second mode, is linked to $\mathrm{P}_{\mathrm{E}}$, the more $\mathrm{P}_{\mathrm{E}}$ is high the more $\mathrm{N}_{\mathrm{s}}$ must be high. So it is necessary of course to give always a look to the strength check of the stretched rod in order that the maximum stress doesn't exceed the steel design stress $f_{d}$.

\section{References}

[1] Belluzzi O., "Contributo allo studio della stabilità dell'equilibrio di aste compresse", Ann. dei Lav. Pub., 1929, 12.

[2] G. Winter, "Lateral bracing of columns and beams", ASCE Trans., 1960, 125.

[3] S. Kitipornchai, D. Finch, " Stiffness requirements for cross bracings”, J. of Str. Eng., ASCE, 1986, 112
[4] A. Picard, D. Beaulieu, "Design of diagonal cross bracing", Eng. J., AISC, 1987, 24

[5] T. Galambos, P. Green, T. Helwig, J. Yura, “ Basic design for stability”, AISC-SSRC Short Course, 2003

[6] Z. Fan, T. Helwig,"Behaviour of steel box girders with top flange bracing", J. of Str. Eng., ASCE, 1999, 125

[7] AASHTO/NSBA Steel Bridge Collaboration, "G13.1 Guidelines for steel girder bridge analysis", 2011 Washington, D.C.

[8] J. Yura, Widianto,"Lateral buckling and bracing of beams", Proceedings of Structural Stability Research Council, Annual Stability Conference, 2005

[9] T. Helwig, J. Yura,"Steel bridge design handbook: bracing system design", Publication No.FHWA-IF-12-052 - vol. 13, 2012

[10] NTC2008,"Norme Tecniche per le Costruzioni”, D.M.14.01.2008

[11] IS 800-1993,"Code of Practice for General Construction in Steel", Bureau of Indian Standard 